\title{
Effect of Guava Powder Addition on Epigallocatechin Gallate (EGCG) Content of Green Tea and Its Antioxidant Activity
}

\author{
Hanifah Ridha Rabbani ${ }^{1}$, Djoko Agus Purwanto ${ }^{2}$ Isnaeni $^{2} *$ \\ ${ }^{1}$ Master of Pharmaceutical Science, Faculty of Pharmacy, Universitas Airlangga, Surabaya \\ ${ }^{2}$ Department of Pharmaceutical Chemistry, Faculty of Pharmacy, Universitas Airlangga, Surabaya \\ *Corresponding author: isna.yudi@gmail.com
}

Submitted: 9 Desember 2019

Accepted: 8 Januari 2020

Published: 29 Februari 2020

\begin{abstract}
Background: Tea (Camelia sinensis) contains polyphenols including epigallocatechin gallate (EGCG) which is acknowledged to have strong antioxidant properties. However, its stability is strongly influenced by environment. In a neutral and alkaline environment, EGCG could undergo degradation and lose its antioxidant property. There are some researches about the effect of combination of green tea and other plants to their antioxidant capacity. Objective: The research aimed to investigate the effect of guava addition to EGCG content of green tea and their antioxidant activity. Methods: The concentration of EGCG was determined by chromatographic analysis using TLC scanner, meanwhile the antioxidant activity was evaluated by its ability in scavenging 2,2diphenyl-1-picrylhydrazyl (DPPH) using UV-Vis Spectrophotometer. Results: Among all the samples, formula 4 ( 2 parts of green tea and 3 parts of guava) gave the highest EGCG content (39.03 $\pm 3.65 \mathrm{mg} / \mathrm{g}$ ). This was $37.5 \%$ higher than the control sample $(28.39 \pm 2.45 \mathrm{mg} / \mathrm{g})$. Formula 4 also had the best antioxidant activity with $I_{50}$ of $1917.32 \pm 1.75 \mathrm{ppm}, 19 \%$ lower than control sample (2356.46 $\pm 3.16 \mathrm{ppm})$. Conclusion: The addition of guava powder significantly increased the amount of EGCG in green tea extracts and their antioxidant activity.
\end{abstract}

Keywords: green tea, Camellia sinensis, guava, epigallocatechin gallate (EGCG), antioxidant activity

\section{INTRODUCTION}

In recent years, tea (Camellia sinensis) has developed into the center of attention because of its health benefits, primarily as an antioxidant and anticarcinogenic agents. Flavonoids are commonly believed to play important role in these benefits (Wang et al., 2003). A glass of tea can contain about $300-400$ $\mathrm{mg}$ of total polyphenols. Polyphenols have great antioxidant capacity and can shield body cells from the harmful side effects of reactive oxygen species. Dry tea leaves contain about $42 \%$ polyphenols in the form of catechins. The most common types of catechin inside the tea are epigallocatechin gallate (EGCG), epigallocatechin (EGC), epicatechin gallate (ECG), and epicatechin (EC). EGCG contributes to $13 \%$ of the total polyphenols in tea (Ramalakshmi \& Rao, 2011).

One of the obstacles encountered during the application of tea is the stability of catechins. The stability of catechins including EGCG is strongly influenced by the environment, such as temperature, air, and $\mathrm{pH}$ during storage (Zeng et al., 2018). Tea catechins tend to be less stable at temperatures above $50^{\circ} \mathrm{C}$, even during the heating time at $98^{\circ} \mathrm{C}$; catechins can be degraded up to $20 \%$ (Chen et al., 2001). Catechin degradation will result in decreased antioxidant activity (Dhaouadi et al., 2016). Some solutions that have been applied to maintain the stability of tea catechin were keeping the tea inside refrigerator at $4^{\circ} \mathrm{C}$, setting the $\mathrm{pH}$ of the solution around 4, and the addition of ascorbic acid (Chen et al., 1998). This was in concordance with the work by Fangueiro et al. (2014) which suggested that the existence of ascorbic acid provided great protection to EGCG against degradation.

The utilization of fruit has been known to reduce the degradation of catechins. Dhaouadi et al. (2016) reported that adding pomegranate to green tea significantly reduced the degradation of polyphenol content from $92 \%$ to $36 \%$ in storage for 15 days at $4^{\circ} \mathrm{C}$. The use of lemon juice in tea drinks was also 
known to slow down the degradation of catechins (Bazinet et al., 2010).

There are some researches about the effect of combination of green tea and other plants to their antioxidant capacity (Costa et al., 2012; Nedamani et al., 2015), however, the combination between green tea and pink guava has still not been evaluated. Guava was known to have a high level of ascorbic acid, flavonoids (Yan et al., 2006), and phenolic content (Musa et al., 2015). Therefore in this work, we evaluated the effects of guava addition on EGCG content were evaluated in green tea and their antioxidant activity. The concentration of EGCG was determined by chromatographic analysis using TLC scanner, meanwhile, the antioxidant activity was tested by sample's ability in capturing 2,2-diphenyl-1picrylhydrazyl (DPPH) radicals using UV-Vis Spectrophotometer.

\section{MATERIALS AND METHODS}

\section{Materials}

(-)-Epigallocatechin gallate (EGCG) standard was purchased from Sigma (St. Louis, MO); 2,2-diphenyl1-picrylhydrazyl (DPPH) was acquired from Sigma (Steinheim, Germany); methanol, chloroform, formic acid, and TLC plates $(20 \times 20 \mathrm{~cm})$ pre-coated with silica gel 60 F254 were obtained from Merck (Darmstadt, Germany), ethyl acetate was obtained from Anhui Full Time (Anhui, China); acetone and distilled water were purchased from Smart Lab (Tangerang, Indonesia). All chemicals and reagents were analytical grades.

A commercial green tea (GT) product was purchased from local shop in Surabaya, Indonesia. Each sachet of the product contained $2 \mathrm{~g}$ of green tea powder. As for the fruit, pink guavas $(\mathrm{GV})$ were collected from local market in Surabaya. The pink guavas were produced from plantation in Blitar, Indonesia. The ripe pink guavas which had good appearance were chosen for the study. The guavas were rinsed and peeled to remove the dirt. Clean guavas were then sliced into thin pieces and dried in fruit dehydrator for about 24 hours. Dried slices of guava were turned into powder using dry miller (Miyako Model BL-101 PL).

\section{Instruments}

Chromatographic analysis was performed using CAMAG TLC Scanner 4 (Muttenz, Switzerland) and the data was collected using winCATS software. Spectrophotometric analysis was carried out using Cary 60 UV-Vis Spectrophotometer from Agilent
(California, US) with cuvettes of $1 \mathrm{~cm}$ length. XPE 26 Micro-analytical Balance from Mettler Toledo (Greinfensee, Switzerland) and STARTER 3000 bench $\mathrm{pH}$ meter were also used in this work.

\section{Methods}

\section{Preparation of extracts}

All extracts tested in this research were made freshly. Green tea powder $(2 \mathrm{~g})$ was put into $200 \mathrm{~mL}$ volumetric flask and added with $80^{\circ} \mathrm{C}$ distilled water until the mark. The solution was homogenized using magnetic stirrer for 10 minutes. Green tea extracts then were divided evenly for 5 variations as following: (1) green tea only (GTGV 2:0), (2) green tea added with 1 part of guava powder (GTGV 2:1), (3) green tea added with 2 parts of guava powder (GTGV 2:2), (3) green tea added with 3 parts of guava powder (GTGV 2:3), (4) green tea added with 4 parts of guava powder (GTGV 2:4). Every green tea extracts were then stirred again for another 5 minutes. All the extracts were then filtered to remove the undissolved particles. The extracts were kept in glass bottle at refrigerator if not in use.

\section{Determination of EGCG content in extract}

The extraction of EGCG in all formulas were performed using the method used by Kurniadi et al. (2007) with a minor adjustment. Initially, $2 \mathrm{~mL}$ of filtered samples were partitioned with $2 \mathrm{~mL}$ of chloroform. The chloroform layer was then removed. The water phased was collected and as a second partition, $2 \mathrm{~mL}$ of ethyl acetate was used. This step was repeated twice. The ethyl acetate layer was collected and evaporated inside acid chamber at room temperature. The extract obtained later was reconstituted with $2 \mathrm{~mL}$ of methanol. The quantification of EGCG was done using thin layer chromatography method which was previously used by Vasisht et al. (2003) with slight alteration. Each extracts $(2 \mathrm{~mL})$, and series of EGCG standards, were applied on pre-activated silica TLC plate. All quantitative analysis were made in three replicates. The plate was run in a chamber which was filled with chloroform, acetone, and formic acid with ratio of 5:4:1 as mobile phase. The plate was then dried inside acid chamber and scanned using Camag TLC scanner. The instrument setting as follows: slit dimensions 4.00 x $0.30 \mathrm{~mm}$, scanning speed $20 \mathrm{~mm} / \mathrm{s}$, data resolution $100 \mu \mathrm{m} / \mathrm{step}$, and wavelength $278 \mathrm{~nm}$. The area under curve (AUC) of the EGCG peak was measured and the concentration was determined from the standard plots. 


\section{Determination of antioxidant activity}

The DPPH scavenging activities were carried out using the method developed by Dhaouadi et al. (2016) with slight modifications. First, the extracts were diluted with distilled water to make series of concentrations. The same amount of diluted extracts (40 $\mu \mathrm{L}$ ) were then mixed with $1960 \mu \mathrm{L}$ DPPH solutions $\left(8.87 \times 10^{-5} \mathrm{~mol} \mathrm{~L}^{-1}\right)$. The solutions were kept in dark for 60 minutes. The absorbance of blank (DPPH solution only) and every GTGV solutions were measured at $515 \mathrm{~nm}$. The antioxidant activity of extracts was expressed as \% inhibition of radical DPPH using equations as following $\left[\left(\mathrm{A}_{0}-\mathrm{A}_{\mathrm{t}}\right) / \mathrm{A}_{0}\right] \times 100$, where $\mathrm{A}_{0}$ was the initial absorbance of DPPH solution only and $A_{t}$ was the absorbance of GTGV solutions after 60 minutes incubation.

\section{Statistical analysis}

All test were done in three replicates. Values were presented as mean $\pm \operatorname{SD}(n=3)$. Statistical analysis was performed using SPSS software (Version 24,
SPSS Inc.). One-way analysis of variance (ANOVA) was used to compare the means of all evaluated parameters. Differences were considered significant if $\mathrm{P}$-value is lower than 0.05 .

\section{RESULTS AND DISCUSSION \\ EGCG content in green tea extract}

EGCG content in green tea extracts are listed in Table 1. Green tea extracts with addition of guava powder had higher EGCG content than control sample (green tea only). The addition of 3 and 4 parts of guava powder significantly increased the total of EGCG in green tea extracts. Among the five formulas of green tea and guava, the combination of 2 parts of green tea and 3 parts of guava gave the highest EGCG content $(39.03 \pm 3.65 \mathrm{mg} / \mathrm{g})$. According to the scanning result of TLC plate (Figure 1), there was no EGCG peak in guava sample, indicated that green tea was the only one that contributed to the amount of EGCG detected.

Table 1. Content of Epigallocatechin gallate (EGCG) detected in combinations of green tea and guava extracts

\begin{tabular}{cc}
\hline Formula & EGCG content $(\mathrm{mg} / \mathrm{g})$ \\
\hline GT:GV 2:0 & $28.39 \pm 2.45^{\mathrm{a}}$ \\
\hline GT:GV 2:1 & $31.41 \pm 0.75^{\mathrm{ab}}$ \\
\hline GT:GV 2:2 & $30.80 \pm 0.49^{\mathrm{a}}$ \\
\hline GT:GV 2:3 & $39.03 \pm 3.65^{\mathrm{c}}$ \\
\hline GT:GV 2:4 & $37.90 \pm 3.30^{\mathrm{bc}}$ \\
\hline
\end{tabular}

Data are means \pm standard deviation $(\mathrm{n}=3)$. Figures with different letters are statistically different at $\mathrm{P}<0.05$ as processed by the Tukey HSD test.

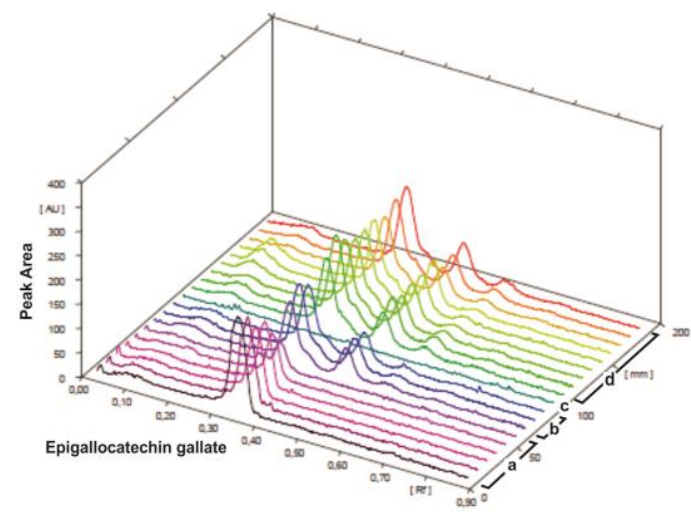

Figure 1. Scanned TLC plate showing the peaks obtained from (-)-Epigallocatechin gallate (EGCG) standard (a), green tea extract (b), guava extract (c), green tea added with guava extract (d). All extracts were obtained using liquid-liquid extraction

Lin \& Yin (2012) reported that no epicatechin detected in guava aqueous extract. Rojas-Garbanzo et al. (2017) analyzed guava fruit using UHPLC-DADMS/MS and reported that it contained epigallocatechin gallate and other catechin compounds but due to overlapping peaks and low intensities, the quantification of those compounds was not achieved. EGCG in guava was not detected in this study probably due to its small concentration.

The increase of EGCG content in extracts added with guava fruit shown in Table 1 was likely due to the ability of guava to reduce the $\mathrm{pH}$ of the solution from 
6.08 to 4.65 . EGCG is known to less stable in solution form. It was noted that $\mathrm{pH}$ affected the stability of EGCG. At neutral and alkaline environment $(\mathrm{pH}>$ 5.5), EGCG could undergo auto-oxidation, yielding dimers such as theasinensin A. Meanwhile acidic environment ( $\mathrm{pH}=2-5.5)$ enhanced the stability of EGCG (Krupkova et al., 2016). Bazinet et al. (2010) previously reported in their work that adjusting the acidity of green tea solution to $\mathrm{pH} 3.8-4.0$ by lemon juice addition increased the stability of EGCG during long-term storage.

It is also speculated that ascorbic acid from guava increased the stability of EGCG. Ascorbic acid was reported significantly stabilized catechins in alkaline solution. Since ascorbic acid is known as antioxidant, it may work as reductant to protect the catechin in green tea. Another assumption, ascorbic acid may decrease the oxidation of catechin in green tea by reducing the concentration of dissolved oxygen in solution (Chen et al., 1998). This was in agreement with the reports by Fangueiro et al. (2014), who examined the stability of EGCG which was spiked with ascorbic acid and found that ascorbic acid could reduce the degradation of EGCG by $80 \%$.
The ability of fruits on stabilizing EGCG is consistent with previous reports explained that pomegranate syrup stabilized green tea catechins content during 15 days storage (Dhaouadi et al., 2016). The high level of sugar in pomegranate syrup was suggested made a role in maintaining catechins stability. The previous study by $\mathrm{Xu}$ et al. (2014) explained the effect of viscosity in maintaining the stability of green tea infusion. It was reported that higher viscosity improved the stability of green tea infusion while being kept in cool terperature.

\section{Antioxidant activities of green tea extracts}

DPPH is a stable radical compound that absorbs visible light at a wavelength of $515-517 \mathrm{~nm}$ (Apak et al., 2013). The DPPH test measures the antioxidant properties of a compound based on their ability to capture DPPH radicals. DPPH free radicals can accept hydrogen atoms or electrons from antioxidants and form non-radical DPPH molecules. The antioxidant activity of green tea was observed from the change in color of DPPH solution which was originally dark purple to pale yellow. Table 2 shows the DPPH scavenging activity of green tea with and without the addition of guava.

Table 2. Antioxidant activities of the combination of green tea and guava extracts

\begin{tabular}{|c|c|c|c|c|c|c|c|}
\hline \multirow{2}{*}{ Formula } & \multicolumn{6}{|c|}{ Antioxidant activity (\%) } & \multirow{2}{*}{$\mathrm{IC}_{50}(\mathrm{ppm})$} \\
\hline & $\mathrm{C}=500 \mathrm{ppm}$ & $1000 \mathrm{ppm}$ & $1500 \mathrm{ppm}$ & $2000 \mathrm{ppm}$ & $2500 \mathrm{ppm}$ & $3000 \mathrm{ppm}$ & \\
\hline $\begin{array}{c}\text { GTGV } \\
2: 0\end{array}$ & $14.77 \pm 0.04$ & $26.98 \pm 0.04$ & $35.08 \pm 0.04$ & $45.84 \pm 0.01$ & $43.02 \pm 0.06$ & $59.63 \pm 0.10$ & $2356.46 \pm 3.16^{\mathrm{a}}$ \\
\hline $\begin{array}{c}\text { GTGV } \\
2: 1\end{array}$ & $15.60 \pm 0.04$ & $26.19 \pm 0.06$ & $37.40 \pm 0.04$ & $47.58 \pm 0.05$ & $57.34 \pm 0.32$ & $64.76 \pm 0.07$ & $2176.88 \pm 6.54^{b}$ \\
\hline $\begin{array}{c}\text { GTGV } \\
2: 2\end{array}$ & $16.63 \pm 0.01$ & $24.90 \pm 0.05$ & $32.98 \pm 0.10$ & $43.37 \pm 0.03$ & $51.50 \pm 0.05$ & $61.58 \pm 0.02$ & $2388.63 \pm 1.28^{c}$ \\
\hline $\begin{array}{c}\text { GTGV } \\
2: 3\end{array}$ & $28.05 \pm 0.04$ & $30.37 \pm 0.02$ & $40.47 \pm 0.03$ & $52.96 \pm 0.02$ & $60.39 \pm 0.03$ & $69.82 \pm 0.01$ & $1917.32 \pm 1.75^{\mathrm{d}}$ \\
\hline $\begin{array}{c}\text { GTGV } \\
2: 4\end{array}$ & $16.40 \pm 0.05$ & $27.49 \pm 0.02$ & $40.98 \pm 0.01$ & $51.88 \pm 0.04$ & $59.04 \pm 0.01$ & $69.07 \pm 0.02$ & $2025.87 \pm 2.19^{\mathrm{e}}$ \\
\hline
\end{tabular}

Data are means \pm standard deviation from three replicates. For $\mathrm{IC}_{50}$ column, figure followed by different letter have statistical difference at $\mathrm{P}<0.05$ as analyzed by the Tukey HSD test.

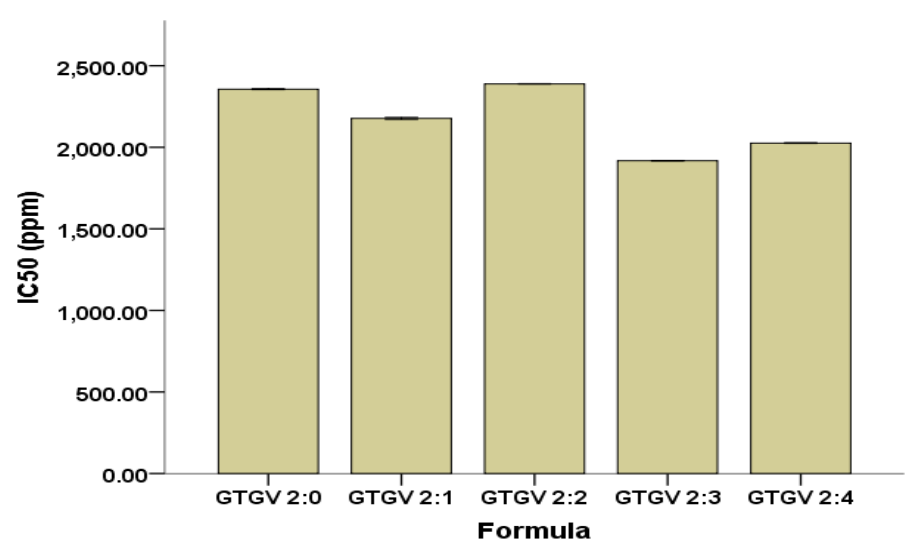

Figure 2. Antioxidant activity of green tea extracts with and without guava addition expressed as $\mathrm{IC}_{50}$ 
The radical scavenging activity (RSA) for green tea extracts at different levels indicate a higher concentration of sample provided higher scavenging activity. This result is due to the increasing number of EGCGs that can donate their hydrogen atoms to DPPH radicals. It was reported that hydroxyl groups in $\mathrm{B}$ ring and a gallate esterified at C ring of EGCG structure contribute to the antioxidant capacity of EGCG (Krupkova et al., 2016).

The effect of guava addition to green tea infusion was shown in Figure 2. Green tea infusion with the presence of guava had significant $(P<0.05)$ lower $\mathrm{IC}_{50}$ value than green tea infusion alone. Formula 4 which contained 2 parts of green tea and 3 parts of guava had the smallest $\mathrm{IC}_{50}$ value $(1917.32 \pm 1.75 \mathrm{ppm})$. The value of $\mathrm{IC}_{50}$ represents the amount of sample needed to scavenge $50 \%$ of DPPH radicals. The lower $\mathrm{IC}_{50}$ value means the higher DPPH radical scavenging activity. Obtained results suggested that the addition of guava powder was able to significantly strengthen the antioxidant activity of green tea up to $19 \%$.

The antioxidant activity of the combination formulas was also affected by the presence of other flavonoids in green tea and guava. Green tea was reported to contain other flavonoids besides EGCG, such as catechin, epicatechin, quercetin-3-rutinoside, kaempferol-3-rutinoside, myricetin-3-glucoside, hesperetin-7-rutinoside, and naringenin-7-rutinoside (Pekal et al., 2012). It has been found that guava also has antioxidant activity due to its flavonoid and phenolic contents (Yan et al., 2006; Musa et al., 2015). The flavonoids detected in the pink guava were kaempferol, isorhamnetin, myricetin, luteolin, and quercetin (Musa et al., 2015). Another study by Nunes et al. (2016) examined guava using HPLC-DAD and the phenolic compounds of guava were myricetin, quercetin, quercetin-3-O-rutinoside, naringenin, 3-4dihydroxybenzoic acid, 2-hydroxybenzoic acid, benzoic acid, gallic acid, syringic acid, 3hydroxycinnamic acid, ferulic acid, rosmarinic acid, and 3,4-dihidroxyphenylacetic acid. Lin \& Yin (2012) also reported that guava aqueous extract contained several compounds, such as ascorbic acid, rutin, quercetin, rosmarinic acid, myricetin, caffeic acid, naringenin, coumaric acid, ferulic acid, and ellagic acid.

\section{CONCLUSION}

In general, the addition of guava powder significantly increased the amount of EGCG in green tea extracts. Among all the samples, formula 4 (2 parts of green tea and 3 parts of guava) gave the highest EGCG content (37.5\% higher than the control sample). The ability of guava to reduce the $\mathrm{pH}$ of the solution and the presence of ascorbic acid were considered able to maintain the stability of EGCG. The presence of guava also enhanced the antioxidant activity of green tea solution up to $19 \%$. The results were likely due to the combined effect of flavonoids contained in green tea and guava.

\section{REFERENCES}

Apak, R., Gorinstein, S., Böhm, V., Schaich, K. M., Özyürek, M. \& Güçlü, K. (2013). Methods of Measurement and Evaluation of Natural Antioxidant Capacity/Activity (IUPAC Technical Report). Pure and Applied Chemistry; 85; 957-998.

Bazinet, L., Araya-Farias, M., Doyen, A., Trudel, D. \& Têtu, B. (2010). Effect of Process Unit Operations and Long-term Storage on Catechin Contents in EGCG-enriched Tea Drink. Food Research International; 43; 1692-1701.

Chen, Z., Zhu, Q. Y., Tsang, D. \& Huang, Y. (2001). Degradation of Green Tea Catechins in Tea Drinks. Journal of Agricultural and Food Chemistry; 49; 477-482.

Chen, Z. Y., Zhu, Q. Y., Wong, Y. F., Zhang, Z. \& Chung, H. Y. (1998). Stabilizing Effect of Ascorbic Acid on Green Tea Catechins. Journal of Agricultural and Food Chemistry; 46; 25122516.

Costa, A. S. G., Nunes, M. A., Almeida, I. M. C., Carvalho, M. R., Barroso, M. F., Alves, R. C. \& Oliveira, M. B. P. P. (2012). Teas, Dietary Supplements and Fruit Juices: A Comparative Study Regarding Antioxidant Activity and Bioactive Compounds. LWT - Food Science and Technology; 49; 324-328.

Dhaouadi, K., Belkhir, M., Raboudi, F. \& Mecha, E. (2016). Pomegranate and Mint Syrup Addition to Green Tea Beverage Stabilized Its Polyphenolic Content and Biofunctional Potentials During Refrigerated Storage. Journal of Food Science and Technology; 53; 1164-1177.

Fangueiro, J. F., Parra, A., Silva, A. M., Egea, M. A., Souto, E. B., Garcia, M. L. \& Calpena, A. C. (2014). Validation of a High Performance Liquid Chromatography Method for the Stabilization of Epigallocatechin Gallate. International Journal of Pharmaceutics; 475; 181-190.

Krupkova, O., Ferguson, S. J. \& Wuertz-Kozak, K. 
(2016). Stability of (-)-Epigallocatechin Gallate and Its Activity in Liquid Formulations and Delivery Systems. Journal of Nutritional Biochemistry; 37; 1-12.

Kurniadi, M., Leswara, N. D. \& Rinayanti, Y. (2007). Analisis Epigalokatekin Galat dalam Minuman Teh Hijau Siap Saji. Majalah Ilmu Kefarmasian; 4; 81-91.

Lin, C. \& Yin, M. (2012). Renal Protective Effects of Extracts from Guava Fruit (Psidium guajava L.) in Diabetic Mice. Plant Foods for Human Nutrition; 67; 303-308.

Musa, K. H., Abdullah, A. \& Subramaniam, V. (2015). Flavonoid Profile and Antioxidant Activity of Pink Guava. ScienceAsia; 41; 149-154.

Nedamani, E. R., Mahoonak, A. S., Ghorbani, M. \& Kashaninejad, M. (2015). Evaluation of Antioxidant Interactions in Combined Extracts of Green Tea (Camellia sinensis), Rosemary (Rosmarinus officinalis) and Oak Fruit (Quercus branti). Journal of Food Science and Technology, 52; 4565-4571.

Nunes, J. C., Lago, M. G., Castelo-Branco, V. N., Oliveira, F. R., Torres, A. G., Perrone, D. \& Monteiro, M. (2016). Effect of Drying Method on Volatile Compounds, Phenolic Profile and Antioxidant Capacity of Guava Powders. Food Chemistry; 197; 881-890.

Pekal, A., Drozdz, P., Biesaga, M. \& Pyrzynska, K. (2012). Screening of the Antioxidant Properties and Polyphenol Composition of Aromatised Green Infusions. Journal of the Science of Food and Agriculture; 92; 2244-2249.

Ramalakshmi, R. \& Rao, J. M. L. (2011). Recent Trends in Soft Beverages. India: Woodhead Publishing India.

Rojas-Garbanzo, C., Zimmermann, B. F., SchulzeKaysers, N. \& Schieber, A. (2017). Characterization of Phenolic and Other Polar Compounds in Peel and Flesh of Pink Guava (Psidium guajava L. cv. 'Criolla') by Ultra-High Performance Liquid Chromatography with Diode Array and Mass Spectrometric Detection. Food Research International; 100; 445-453.

Vasisht, K., Sharma, P. D., Karan, M., Rakesh, D. D., Vyas, S., Sethi, S. \& Manktala, R. (2003). Study to Promote the Industrial Exploitation of Green Tea Polyphenols in India. Vienna: United Nations Industrial Development Organisation.

Wang, H., Provan, G. \& Helliwell, K. (2003). The Functional Benefits of Flavonoids: the Case of Tea. Cambridge: Woodhead Publishing Limited.

Xu, Y., Chen, G., Du, Q., Que, F., Yuan, H. \& Yin, J. (2014). Sediments in Concentrated Green Tea During Low-temperature Storage. Food Chemistry; 149; 137-143.

Yan, L. Y., Teng, L. T. \& Jhi, T. J. (2006). Antioxidant Properties of Guava Fruit: Comparison with Some Local Fruits. Sunway Academic Journal; 3; 9-20.

Zeng, J., Xu, H., Cai, Y., Xuan, Y., Liu, J., Gao, Y. \& Luan, Q. (2018). The Effect of Ultrasound, Oxygen and Sunlight on the Stability of (-)Epigallocatechin Gallate. Molecules; 23; 2394. 